\title{
Performance Management and Quality Assurance in Primary Healthcare Institutions
}

\author{
Camelia Lucia Bakri', Maria Daniela Pipaş ${ }^{2}$

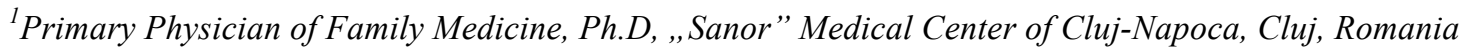 \\ camelia_bakri@yahoo.com \\ ${ }^{2}$ Associate Professor, Ph.D., Faculty of Economics, Management-Finance-Accounting Department, \\ “Bogdan Vodă” University of Cluj-Napoca, Cluj-Napoca,Romania,dpipas@yahoo.com
}

\begin{abstract}
Applying the new health reform gives an unprecedented interpretation to most of the definitions known under a certain form in the socio-economic, general and managerial relationships in particular. In this context, most specialists support the definition of quality of care by optimal patient care based on the use of standard treatment protocols, additional and individual services that are applied in the system of interactions and interpersonal relationships between physician and patient. Obviously, the way in which healthcare managers are addressing quality differs greatly according to organizational culture, personality, experience and training. Good quality management consists of planning, organizing, practical implementation, leadership by applying the most effective organizational decisions, control and evaluation, and last but not least, reviewing the necessary measures to model management services and processes so that they can respond permanently to the most stringent needs of beneficiaries, suppliers, financiers, etc.
\end{abstract}

KEYWORDS: quality, health, management, patient, treatment

\section{Introduction}

The concept of quality is a very broad concept that generally involves the existence of three fundamental characteristics (Gheorghe 2006, 192):

1. professional quality - which means that both the product and the services fulfill the necessary conditions established by the standards of medical practice. Because the degree of the practitioner's professional satisfaction is directly related to the quality of the medical act, but also takes into account the context in which he/she works. In this respect it can be said that the existence of organizational satisfaction leads to an increase of the individual and organizational performance;

2. the quality from the point of view of the beneficiary (patient satisfaction). Normally, patients do not have the necessary knowledge to assess the technical competence of the health care provider, but they know best in what state their health is, their treatment, and how they have been treated, also to what degree their needs/expectations were fulfilled. Patients often limit themselves to asking questions, and they evaluate medical services as being convenient or not. The existence of this dimension of quality leads to the development of positive/negative behaviors from patients (acceptance/non-acceptance of recommendations, increased/low treatment compliance, continuity/discontinuation of treatment, decrease/increase of treatment abandonment rate, etc.). Sometimes patients' expectations are much higher than what the doctor can offer, or they may be rigid and tend to resist what they regard as interference with strictly personal issues. For this reason, the patient's perception can be considered a consequence and not an attribute of health services;

3. total quality management - Total quality management can be considered as an organizational model that attests to the participation of all organizational factors in order to develop and implement the process of improvement of quality that can meet or exceed the expectations of the beneficiaries. This organizational model takes into account the premise that $90 \%$ of all the issues addressed are process-related problems, not staffing issues. The principles of total quality are represented by the focus on the recipient of medical services, teamwork and continuous improvement of quality.

According to ISO8402/1995, the definition of quality is: "The set of characteristics of an entity, that gives it the ability to meet known and potential needs of the user". 
In general, the concept of quality has economic, social, philosophical and technical meanings and is used in various fields. As a general definition, the literature highlights various derivatives that emphasize certain aspects:

1. J.M. Juran $(1988,23)$ says that quality is: "the ability through which certain needs are satisfied or the level at which the product can successfully serve the expectations of consumers";

2. According to Grönroos' theory (Grönroos 2007, 38): "quality represents the full satisfaction of customers' wishes";

3. Stanciu I. $(2003,65)$ considers quality as: "the level at which processes, services and products reach and even exceed the expectation level as well as the requirements of consumers";

4. Al-Hawari (2006, 228): "quality is the main cause of business performance";

5. Kara Henson \& Co. (Sheikh, Gilson, Agyepong, Hanson, Ssengooba, Bennett 2011, 8) argue that: "High-quality healthcare services or products are those that relate to effective care and meet the needs and expectations of all, respecting the criteria of humanity, equity and efficiency".

The complexity of quality is given by the multitude of existing definitions, all the above-mentioned definitions presenting different conceptual points of view, as well as due to the determinant factors that are referred to (Raboca 2013, 5).

\section{Evolution and attributes of quality}

In the field of health, Etco Constantin (2006, 636) says: "through quality we understand, to a large extent, the proper conduct of risk-free interventions, which the public health system can cover in terms of costs, which have the ability to meet the patient's reasonable needs and expectations and to produce a favorable impact on the morbidity, disability and mortality of the population." In other words, quality means doing the right thing at the right time and in the right way.

In the computerized society, patient expectations are formed also by assessing the technologies used and applied in health units, by comparing the quality of interpersonal relationships, communication and psychosocial support offered to patients.

Healthcare institutions in most developed countries have a department specifically created to control quality issues, in charge of planning and implementing a total quality management system (MCT), which implies an understanding of the principles related to quality improvement according to Table 1.

Table 1. Several principles related to quality improvement in sanitary units (Raboca 2013,5)

\begin{tabular}{|l|l|}
\hline \multicolumn{3}{|c|}{ Total quality management system for healthcare facilities } \\
\hline & $-\begin{array}{l}\text { quality requires conscious and sustained involvement of all employees } \\
\text { in the organization }\end{array}$ \\
\cline { 2 - 3 } $\begin{array}{l}\text { Principles related } \\
\text { to quality } \\
\text { improvements }\end{array}$ & $\begin{array}{l}\text { quality must be clearly perceived by the beneficiaries of the health } \\
\text { services (patients), in this sense it is necessary for the healthcare } \\
\text { institution to take into account the needs of the consumer both in the } \\
\text { planning, designing, producing and activities made in the provision of } \\
\text { quality medical services }\end{array}$ \\
\cline { 2 - 3 } & $-\begin{array}{l}\text { quality involves collaboration with all partners involved in the } \\
\text { delivery of quality medical services (suppliers of equipment, } \\
\text { medicines, high-performance medical services, etc.). }\end{array}$ \\
\cline { 2 - 3 } & $-\begin{array}{l}\text { quality does not refer to and is not limited only to medical services, it } \\
\text { must be found in all the activities carried out by the health care } \\
\text { institution. }\end{array}$ \\
\cline { 2 - 3 } & $\begin{array}{l}\text { quality is a necessary element, but sometimes it may prove to be } \\
\text { insufficient, especially if partners/competitors do not act in the same } \\
\text { direction }\end{array}$ \\
\hline
\end{tabular}




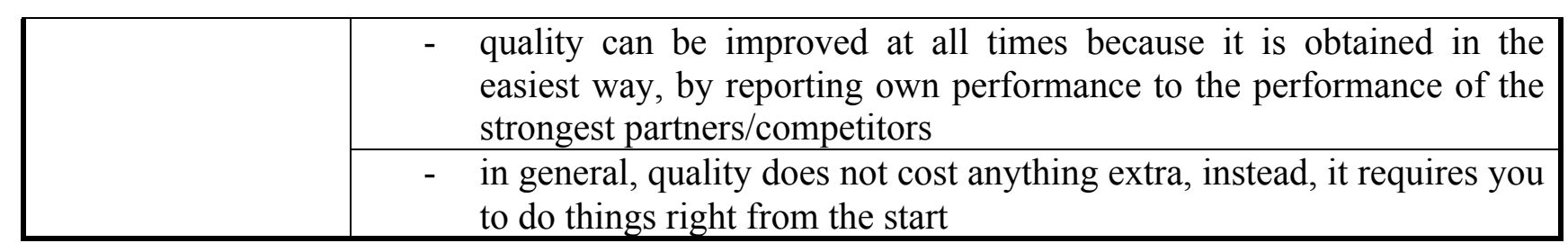

\section{General framework on performance in the health system}

There is a wide variation in health outcomes for countries with similar levels of income and education. Some variations are due to differences in health system performance. Differences in form, content, and management of health systems translate into socially measured results such as health, ability to respond to population expectations or equity.

Decision-makers at all levels need to quantify the variation in health system performance, to identify the factors that influence it and formulate policies that will generate better outcomes in a variety of situations. At the level of the country regions, it is also necessary to evaluate the performance of the system subcomponents (Preston 1986, 34-40).

In the OMS vision, the concept of performance is around three fundamental criteria:

1. Improving the health state;

2. Maximizing the possibility of responding to the needs and expectations of the population;

3. Ensuring fairness and equity in relation to financial contribution.

Cristopher Murray and Julio Frenck (Murray \& Frenck 2000, 1) propose a general framework for understanding the performance of health systems. They believe that a convincing and operational framework for assessing the performance of a health system is vital for the work of governments, development agencies and multilateral institutions.

A major application of this framework is the structuring of the World Health Report's statistical annexes. Since 2000, this report has provided information on the health system's performance of each country:

a. Improving health, which is the founding principle of the health system, means at the same time improving people's health and reducing inequality and discrimination procedures;

b. Maximizing the capacity to respond to the needs and expectations of the population includes two major components:

- respect for the person (including respect for human dignity, confidentiality and autonomy of individuals and families with regards to decisions affecting their own health);

- orientation towards customer/patient (including prompt delivery of healthcare, access to social support networks during care, quality of basic services and free choice of service provider) (WHO - The World Health Report 2000).

c. Ensuring fairness related to financial contribution means that each household pays a fair share of a country's total health spending (which may mean that any poor household does not pay anything). This implies the fact that everyone is protected of financial risks related to health care (McKee \& Healy 2002, 112).

Measuring the performance of health systems links the achievement of the basic goals (the three pillars) and the resources available. Performance can be judged by comparing how the basic goals of the healthcare system have been reached in the ideal way in which the goals could have been achieved, given the resources.

The World Health Organization has defined health for over 50 years as "full physical, mental and social well-being, and not just the absence of disease or disability". The World Health Organization approach has the merit of capturing the positive and partially subjective nature of the concept of health. Whatever the definition of health, it is important to differentiate its determinants: behaviors, biological factors, physical and social environment that influence health.

The state of health of the population and the health protection are closely related to the medical and social problems of the population, to the correlations between the socio-economic development and the evolution of the public health and health organization (macrosociology 
problems), social factors (social-economic agents) as health risk factors and health protection factors, climate in working collectives, family issues, internal sociology of sanitary units, the level of health culture, and the health behavior of the population.

In Romania, as in all ex-communist countries, prioritization of health services with universal access is a matter of high relevance. We can distinguish two major aspects: budgets allocated for health care are very low, limiting the provision of all the health services required by physicians and the population, as well as many effective interventions, being neglected both economically and medically, underfunded or provided at reduced qualitative standards when exactly this type of intervention should have a higher priority and benefit from important resources, having the certainty of a positive impact on the health of the population using the essential healthcare package. In our country, when mentioning the state in relation to medical services, we can refer to central or local level structures such as: the Ministry of Health, the National Health Insurance House, the Public Health Department, the County Health Insurance Houses, or County Councils and Town Halls that also have some health responsibilities.

Sanitary authorities are responsible for health care of the population, needing to streamline health care as long as their budgets are finite and must decide what healthcare services to provide (minimum package or on demand), thus we can see a streamlined model of medical services such as: primary care, where the GP decides if the patient needs additional investigations or treatments, waiting lists, professional autonomy that leads to patients' confidence that the decisions made on their treatment are taken on strictly medical rather than administrative criteria.

A healthcare system can be characterized and evaluated taking into account two of the most important aspects: its organization and the financial flow of its activities. Taking into account the financial flow, three categories can be identified: the payer, the supplier and the consumer (the patient). According to the literature, the financing methods of the healthcare system can be: National Health Systems where we see funding from global taxes being redistributed through the State Budget, health insurance schemes based on mandatory contributions to the special health fund, Private Insurance Health Systems based on voluntary insurance premiums, Direct Payment in which the patient pays his/her medical services directly whenever he/she needs them or Copayment where the patient pays in addition to the health insurance he/she benefits of.

In this context, based on the requirements of the human society, social and economic interests appear in the health care system, highlighting at least three basic aspects with different sociological levels such as: patients who are interested in receiving the services as operatively as possible, for the services to be cheap and of high quality, medical staff who are interested in material and moral self-confirmation (salary, working conditions, assertiveness and respectability perspectives), administrative and management structures of the medical sector.

\section{Conclusions}

Health is an indisputable and immeasurable resource of the human being, of the individual and society as a whole, considered to be one of the most important national values. In this respect, the assessment of health services and programs is the main desideratum of all developed countries.

Quality that must be perceived by patients in the provision of medical services requires cooperation with "quality" partners, performing medical institutions, modern equipment suppliers, medicines, sanitary materials, reagents and competitive and qualitative foods.

Quality can always be improved and this can be achieved by comparison with other institutions of the same kind, or by reporting your own performance to the most powerful competitors or partners. Quality does not cost anything extra, but you have to do things right the first time. Quality assurance is a systematic process, aimed at continuously improving the performance of medical care.

A healthcare institution must provide a high level of employee satisfaction by motivating them to improve their knowledge and to seek new solutions to the institution's problems, and as a result, we will see superior quality medical services. Thus, the quality of sanitary services is interpreted as optimal care of the patient, based on the use of standard treatment protocols. 


\section{References}

Al-Hawari, M. 2006. "The effect of automated service quality on bank financial performance and the mediating role of customer retention." Journal of Financial Services Marketing, Vol. 10, No 3, ABI/INFORM Global, Accessed Fabruary 15, 2019.

Ețco, Constantin. 2006. Mangement în sistemul de sănătate (Management in the health system). Chișinău: Epigrafic Publishing House.

Gheorghe, Ingrid Laura. 2006. Managementul spitalului (Hospital management). Bucharest: Public H Press Publishing House.

Grönroos, Christian. 2007. Service Management and Marketing: Customer Management in Service. New-York, 3 edition, JW.

Juran, J.M., Frank M. Gryna. 1988. Juran's Quality Control Handbook. London, 4th edition, Mcgraw-Hill (Tx); 4th edition.

McKee, M. and Healy, J. 2002. Hospitals in a changing Europe, European Observatory on Health Care Systems, Open University Press.

Murray, Christopher J. L. and Frenk Julio. 2000. "A framework for assessing the performance of health systems." Bulletin of the World Health Organisation 78 (6).

Preston, SH. 1986. Mortality and development revisited, New York, Population Bulletin of the United Nations, 18.

Raboca, Horia Mihai. 2013. Managementul calității $\hat{\imath}$ administrație publică (Quality Management in Public Administration). Bucharest: Tritonic Publishing House.

Stanciu, I. 2003. Managementul calităţii totale (Total quality management). Bucharest: The University Book Publishing House.

Sheikh, K., Gilson L., Agyepong IA, Hanson K., Ssengooba F., Bennett S. 2011. Building the field of health policy and systems research: framing the questions, PLoS medicine, 8 (8), e1001073. ISSN 1549-1277 DOI: 10.1371/journal.pmed.1001073, Accessed February 2, 2019. http://researchonline.lshtm.ac.uk/ 85/1/pmed. 1001073.pdf.

** * SR ISO 8402:1995, Quality managment and quality assurance. 